\title{
Description and typology of intensive Chios dairy sheep farms in Greece
}

\author{
A. I. Gelasakis, ${ }^{1}$ G. E. Valergakis, G. Arsenos, and G. Banos \\ Department of Animal Production, School of Veterinary Medicine, Aristotle University of Thessaloniki, Thessaloniki 54124, Greece
}

\begin{abstract}
The aim was to assess the intensified dairy sheep farming systems of the Chios breed in Greece, establishing a typology that may properly describe and characterize them. The study included the total of the 66 farms of the Chios sheep breeders' cooperative Macedonia. Data were collected using a structured direct questionnaire for in-depth interviews, including questions properly selected to obtain a general description of farm characteristics and overall management practices. A multivariate statistical analysis was used on the data to obtain the most appropriate typology. Initially, principal component analysis was used to produce uncorrelated variables (principal components), which would be used for the consecutive cluster analysis. The number of clusters was decided using hierarchical cluster analysis, whereas, the farms were allocated in 4 clusters using k-means cluster analysis. The identified clusters were described and afterward compared using one-way ANOVA or a chi-squared test. The main differences were evident on land availability and use, facility and equipment availability and type, expansion rates, and application of preventive flock health programs. In general, cluster 1 included newly established, intensive, well-equipped, specialized farms and cluster 2 included well-established farms with balanced sheep and feed/crop production. In cluster 3 were assigned small flock farms focusing more on arable crops than on sheep farming with a tendency to evolve toward cluster 2, whereas cluster 4 included farms representing a rather conservative form of Chios sheep breeding with low/intermediate inputs and choosing not to focus on feed/crop production. In the studied set of farms, 4 different farmer attitudes were evident: 1) farming disrupts sheep breeding; feed should be purchased and economies of scale will decrease costs (mainly cluster 1), 2) only exercise/pasture land is necessary; at least part of the feed (pasture) must be home-grown to decrease costs (clusters 1 and 4), 3) providing pasture to sheep is essential; on-farm feed production decreases costs (mainly cluster 3),
\end{abstract}

Received September 26, 2011.

Accepted February 5, 2012.

${ }^{1}$ Corresponding author: gelasakis.vet@gmail.com and 4) large-scale farming (feed production and cash crops) does not disrupt sheep breeding; all feed must be produced on-farm to decrease costs (mainly cluster 3). Conducting a profitability analysis among different clusters, exploring and discovering the most beneficial levels of intensified management and capital investment should now be considered.

Key words: typology, intensive management system, Chios dairy sheep, multivariate analysis

\section{INTRODUCTION}

Sheep milk production is of great importance for developed Mediterranean countries (Greece, Italy, France, and Spain), contributing significantly to the rural income and enhancing national economy (Haenlein, 2001). In Greece, about 9 million dairy sheep (6.5 million milking ewes) are reared under various traditional farming systems, classified as 1) sedentary extensive, 2) transhumant, 3) semi-intensive, and 4) small intensive (Hatziminaoglou et al., 1992). Annual sheep milk production ranges from 650 to 700 million liters and is transformed to highly valued cheeses (90\%) and yogurt (10\%); 16 sheep milk cheese varieties are produced under the European guaranteed labels of Protected Designation of Origin, with Feta being the most renowned.

Although the majority of flocks are still reared under traditional systems, in the last decade, due to changing socioeconomic conditions, transhumant and small intensive (backyard) flocks are gradually disappearing, to the benefit of larger flocks implementing intensive farming systems (Zygoyiannis, 2006). These systems, whose significance is expected to rise in the future, are characterized by considerable capital investment and their profitability is dependent on high ewe productivity. High-yielding foreign dairy sheep breeds have been imported to Greece (East Friesian in the early past, Lacaune in the late 1990s, and lately the Assaf.E), but in contrast to some other countries, a local breed exists that perfectly fits to intensive systems. The Chios breed is highly productive $(308 \pm 99 \mathrm{~kg}$ of milk in $210 \mathrm{~d}$, with a prolificacy of 1.8-2.2; Papachristoforou and Markou, 2006; Gelasakis et al., 2010) and sought after for this reason. Farming conditions and production methods in Chios sheep flocks have been recently described in de- 
tail (Gelasakis et al., 2010) and a cooperative of Chios sheep breeders has been created, leading to a program of genetic improvement.

Management of these farms remains, however, a critical issue. Increasing productivity through the development of intensified management schemes is a great challenge for the modern sheep industry and, therefore, has been recognized as a major research interest for small ruminants (Haenlein, 2001). According to Coop (1982), the term intensive on livestock production implies a high density or concentration of stock under fairly tight control and managed with the most refined technology of the time. Intensive sheep farming systems are considered as the systems with the greatest labor input per ewe, enjoying the benefit of advanced information and technology (Morand-Fehr and Boyazoglu, 1999). A suitable gradation on the intensity of farming systems is hardly obtainable, however, because it depends on what is considered to be normal intensity in sheep production. Moreover, a noticeable diversity of management schemes exists in intensified dairy sheep farming systems. Describing these systems on an individual basis is, of course, not feasible and, therefore, a need for a representative classification is evident.

For this reason, 2 general approaches are suggested for the development of a farming system's overall descriptor. The first is the a priori approach (Iraizoz et al., 2007), which builds on previous knowledge of farming systems to define the characteristics of their segmentation, providing a qualitative classification on the basis of arbitrary and ad hoc considerations (Köbrich et al., 2003). The second approach uses collected data of characteristics of farming systems to extract, by means of exploratory statistical methodologies [e.g., principal component (PC) analysis (PCA) and cluster analysis (CA)], an a posteriori grouping, representing a quantitative classification (Köbrich et al., 2003). The appropriate typology is provided, based on the assumption that a maximum amount of heterogeneity between the types and a maximum homogeneity within specific types is obtainable. Therefore, such a typology tends to be explanatory or predictive and is recognized as a useful classification tool by the Commission of Agricultural Typology (Kostrowicki, 1977).

The extended geographical distribution of Chios sheep flocks, the diversity of the management strategies adopted (although all of them follow an intensified scheme), their common production objectives, and their significance in the future rural development in Greece render them an appropriate model for an a posteriori classification of farming systems. The objective of this study was to assess the intensified dairy sheep farming systems of Chios breed in Greece, establishing a typology that may properly describe and characterize them.

\section{MATERIALS AND METHODS}

\section{Area of the Study}

All farms that belong to Chios Sheep Breeders' Cooperative Macedonia (66 flocks raising 14,130 ewes), located in Macedonia and Thessaly (Northern and Central part of mainland Greece, respectively) were included in the study. The flocks were distributed in 9 counties (Chalkidiki, Imathia, Pella, Thessaloniki, Kilkis, Magnisia, Larisa, Kozani, and Serres), which are the main areas of Chios breed farming. All farms were located in plain areas devoted to crop production (small grains, maize, alfalfa, cotton, and sugar beets), orchards, and olive groves; however, topography ranged from coastal areas to inland plateaus. The climate was Mediterranean with continental influence in some areas; the average rainfall ranged between 300 and 700 $\mathrm{mm}$, peaking in spring and autumn.

\section{Data Collection and Processing}

A structured direct questionnaire was designed for in-depth interviews. The survey was conducted from June to September 2007 and data was collected by the same veterinarian during extended on-farm visits $(3-5 \mathrm{~h})$. The questions were properly selected to obtain a general description of farm characteristics and overall management practices, and included information about a) farm location and land use, b) flock size and structure, c) facilities and equipment, d) feeding management, e) reproduction and breeding strategies, f) labor force, g) levels of milk and lamb production, and $h$ ) preventive flock health program. The original variables $(\mathbf{O V})$ used for statistical analysis are shown in Table 1. Longitude and latitude were obtained from Google Earth. A ewe replacement rate could not be calculated, as most farms were in an expansion. Artificial insemination is notably absent from the list of variables because it is not used in any farm. Production figures reported were checked and essentially corresponded to official milk production and lambing recordings. For each farm, 2 scores were calculated based on 1) facilities (main and auxiliary sheep barns, milking parlor, roughage storage shed, concentrate storage and mixing sheds, personnel facilities, and ease of road access) and equipment (power generator, bulk milk tank, hammer mill, concentrate mixer, mixer-feeder wagon, automated lamb rearing machine, and restraining equipment) and 2) preventive flock health program (vaccination program against clostridial diseases, contagious agalactia, enzootic abortion, pasteurellosis, gangrenous mastitis, paratuberculosis, anthelminthic and ectoparasite treatment, intramammary antibiotic treatment at dry-off, 
Table 1. Structural and management indicators of dairy sheep farms (mean $\pm \mathrm{SD}$, where applicable)

\begin{tabular}{|c|c|}
\hline Item & $\begin{array}{c}\text { Mean } \pm \mathrm{SD} \\
\text { (where applicable) }\end{array}$ \\
\hline Latitude & $29^{\circ} 11^{\prime} 11^{\prime \prime}-41^{\circ} 20^{\prime} 58^{\prime \prime}$ \\
\hline Longitude & $21^{\circ} 46^{\prime} 44^{\prime \prime}-22^{\circ} 09^{\prime} 26^{\prime \prime}$ \\
\hline Owned surface, ha & $7.6 \pm 10.7$ \\
\hline Rented surface, ha & $11.9 \pm 22.6$ \\
\hline Ewes, $\mathrm{n}$ & $210.3 \pm 138.5$ \\
\hline Lamb ewes, $\mathrm{n}$ & $87.7 \pm 69.9$ \\
\hline Ram replacement, \% & $31.0 \pm 17.3$ \\
\hline Replacement rams, $\mathrm{n}$ & $5.7 \pm 4.9$ \\
\hline Daily grazing time in winter, $\mathrm{h}$ & $1.1 \pm 1.0$ \\
\hline Daily grazing time in summer, $\mathrm{h}$ & $2.1 \pm 2.5$ \\
\hline Hay/ewe per year, $\mathrm{kg}$ & $336.1 \pm 72.9$ \\
\hline Concentrates/ewe per vear. ${ }^{1} \mathrm{~kg}$ & $355.5 \pm 41.4$ \\
\hline Concentrate-to-forage ratio & $0.85 \pm 0.19$ \\
\hline Mating period (mature ewes), ${ }^{2}$ mo & $6.1 \pm 1.1$ \\
\hline $\begin{array}{l}\text { Mating period (second- } \\
\text { parity ewes) }{ }^{1,2} \text { mo }\end{array}$ & $6.5 \pm 1.2$ \\
\hline Mating period (lamb ewes), ${ }^{2}$ mo & $8.6 \pm 1.3$ \\
\hline Milk production/ewe per year $(210 \mathrm{~d})$ & $276.6 \pm 55.6$ \\
\hline Lamb weaning age, $d$ & $52.0 \pm 11.4$ \\
\hline Lambs for slaughter, ${ }^{1} \mathrm{n}$ & $159.5 \pm 111.9$ \\
\hline Age of lambs for slaughter ${ }^{1} \mathrm{~d}$ & $53.3+12.2$ \\
\hline Lamb carcass weight, $\mathrm{kg}$ & $9.9 \pm 1.2$ \\
\hline Facilities and equipment score $(0-17)^{3}$ & $9.5 \pm 3.7$ \\
\hline $\begin{array}{l}\text { Preventive health program score } \\
(0-10)^{3}\end{array}$ & $5.8 \pm 1.7$ \\
\hline
\end{tabular}

${ }^{1}$ Variable excluded from principal component analysis.

${ }^{2}$ January 1 to December 12.

${ }^{3}$ Facilities and equipment score: main and auxiliary sheep barns, milking parlor, roughage storage shed, concentrate storage and mixing sheds, personnel facilities, ease of road access, power generator, bulk milk tank, hammer mill, concentrate mixer, mixer-feeder wagon, automated lamb rearing machine, and restraining equipment. Preventive health program score: vaccination program against clostridial diseases, contagious agalactia, enzootic abortion, pasteurellosis, gangrenous mastitis, paratuberculosis, anthelminthic and ectoparasite treatment, intramammary antibiotic treatment at dry-off, and implementation of quarantine..

and implementation of quarantine). One degree was assigned for each of the facilities and equipment as well as for each of the aforementioned preventive measures; thus, the 2 scores ranged from 0 to 17 and from 0 to 10 , respectively.

\section{Statistical Analysis}

A multivariate statistical analysis was used on the data to obtain the most appropriate typology. The criteria for the selection of the most appropriate variables to use for the typology were their availability and quality of data as well as their relevance (Köbrich et al., 2003; Table 1). The analysis was performed using the SPSS 16 software (SPSS Inc., Chicago, IL) and was carried out in 4 steps.

1) Principal Component Analysis. Initially, the variables were standardized and based on PCA; 4 of them were excluded from further analyses due to their high correlation with 4 other initial variables; namely, concentrates per ewe per year, mating period of second-parity ewes, age of lambs for slaughter, and number of lambs for slaughter were highly correlated with concentrate-to-forage ratio, mating period of ewes, weaning age, and number of ewes, respectively, and only the latter variables from each pair were retained. The rest of the variables were retained for the next steps of PCA. The Kaiser-Meyer-Olkin measure of sampling adequacy was calculated to test the sampling adequacy. Also, Bartlett's test of sphericity was calculated to test whether the correlation matrix is an identity matrix. Only 6 PC had eigenvalues greater than 1 (Kaiser's rule; Kaiser, 1960) and were, therefore, retained for the successive CA (Table 2). The eigenvalues of the $6 \mathrm{PC}$, as well as the percentage of variance and the cumulative percentage of variance they explained, are presented in Table 2. The eigenvectors of weights of the OV are shown in Table 3, where eigenvectors with values higher than 0.4 and lower than -0.4 have been typed in bold. The rotation of the component matrix was performed using Varimax with Kaiser normalization method; the rotated component matrix was used to describe the PC, according to their relationship with the OV; the PC were finally being set as farm profiles, described in Table 4. The recognized farm profiles were used as variables for the hierarchical CA.

2) Hierarchical Cluster Analysis. The optimal number of clusters was identified by means of hierarchical CA based on Ward's method, which optimizes minimum variance within clusters (Köbrich et al., 2003). This method works by merging groups or cases resulting in the minimum increase in the within-group sum of squares or the error sum of squares (Ward, 1963). The agglomeration schedule from which the number of clusters was decided using the elbow rule is shown in Table 5. According to this rule, to assess the ideal number of clusters, it was necessary to plot the number of clusters against the change of the fusion coefficient for each stage (each stage reflects a combination between 2

Table 2. Eigenvalues of the 6 principal components (PC) and percentage of variance they explain

\begin{tabular}{lccc}
\hline & \multicolumn{3}{c}{ Initial eigenvalue } \\
\cline { 2 - 4 } PC & Total & $\begin{array}{c}\text { \% of } \\
\text { variance }\end{array}$ & $\begin{array}{c}\text { Cumulative } \% \\
\text { of variance }\end{array}$ \\
\hline PC1 & 4.52 & 23.80 & 23.80 \\
PC2 & 2.74 & 14.39 & 38.19 \\
PC3 & 2.06 & 10.83 & 49.02 \\
PC4 & 1.64 & 8.63 & 57.65 \\
PC5 & 1.41 & 7.43 & 65.08 \\
PC6 & 1.00 & 5.27 & 70.35 \\
\hline
\end{tabular}


Table 3. Eigenvector weights for each of the 19 original variables according to the principal components ${ }^{1}$

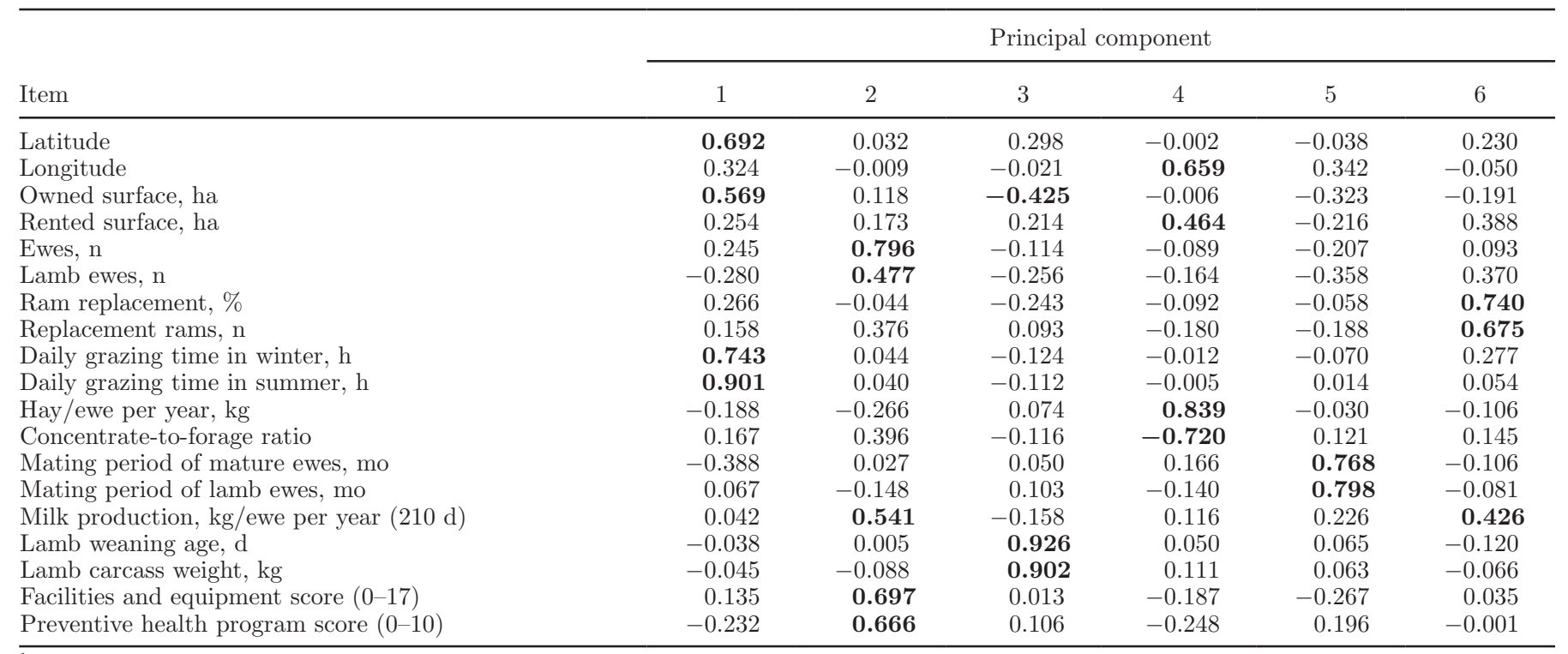

${ }^{1}$ Eigenvectors with values higher than 0.4 and lower than -0.4 are shown in bold.

clusters) and find the 2 stages with the highest jump in the difference between their distance coefficients. This was obvious for stages 62 and 63 (Table 5). Afterwards, the number of stages $(\mathrm{n}=62)$ was subtracted from the number of observations $(\mathrm{n}=66)$; the result indicated the ideal number of clusters for the successive k-means cluster analysis $(\mathrm{n}=4)$.

3) $k$-Means Cluster Analysis. This third step was used to allocate cases into the default number of clusters.

4) Between-Cluster Statistical Analysis. To characterize and compare the identified clusters, means and standard deviations (continuous variables) or frequencies (categorical variables) for the most informative variables including OV were calculated. For continuous variables, the differences between groups were assessed using a one-way ANOVA analysis and thereafter, the least significant difference test was used as a post-hoc test. For categorical variables, the differences between groups were assessed using the $\chi^{2}$ test.

\section{RESULTS}

The Kaiser-Meyer-Olkin measure of sampling adequacy was 0.601, indicating that the factor analysis of variables was appropriate $(>0.500)$; moreover, Bartlett's test of sphericity was significant $(P \leq 0.001)$ and, thus, it could be concluded that the strength of the relationship among variables was high.

The 4 clusters (1, 2, 3, and 4) included 18 (27.3\%), 23 (34.8\%), $16(24.3 \%)$, and $9(13.6 \%)$ farms, respectively. Frequencies, as well as means and standard deviations for the most descriptive categorical and continuous variables of the aforementioned clusters are presented in Tables 6 and 7, respectively.

All clusters shared many common characteristics. Farmer age, ewe BW, mating period of lamb ewes, lamb ewe BW at first lambing, and amount of concentrates per ewe per year were not significantly different among clusters. Adoption of various management practices (steaming up rations, colostrum management, and ar-

Table 4. The description of the novel farm profiles

\begin{tabular}{ll}
$\begin{array}{l}\text { Principal component } \\
\text { (farm profile) }\end{array}$ & Description of farm profile \\
\hline 1 & Large land properties/pasture use \\
2 & Large flocks/high management level and milk production \\
3 & Heavy-weight lamb production \\
4 & Land renters/low concentrate-to-forage ratio \\
5 & Late mating season \\
6 & Intensive ram replacement \\
\hline
\end{tabular}


Table 5. Agglomeration schedule for the hierarchical cluster analysis ${ }^{1}$

\begin{tabular}{lccc}
\hline & \multicolumn{2}{c}{ Clusters combined } & \\
\cline { 2 - 3 } Stage & Cluster 1 & Cluster 2 & Coefficient \\
\hline 54 & - & - & - \\
55 & - & - & - \\
56 & 14 & 45 & 162,057 \\
57 & 2 & 6 & 176,602 \\
58 & 3 & 11 & 191,854 \\
59 & 1 & 23 & 207,323 \\
60 & 1 & 9 & 228,431 \\
61 & 2 & $\mathbf{4 8}$ & 252,543 \\
$\mathbf{6 2}$ & $\mathbf{1 4}$ & 14 & $\mathbf{7 8 , 5 5 2}$ \\
63 & 1 & 3 & 310,498 \\
64 & 2 & 2 & 343,868 \\
65 & 1 & & 390,000 \\
\hline
\end{tabular}

${ }^{1}$ To assess the ideal number of clusters, the number of clusters was plotted against the change of the fusion coefficient for each stage (each stage reflects a combination between 2 clusters) and 2 stages with the highest jump in the difference between their distance coefficients were found. Afterwards, the number of stages $(n=62$, in bold) was subtracted from the number of observations. tificial suckling of lambs) did not differ among the 4 clusters either, regardless of their frequency, which in some cases was very low (see Table 6). Some housing aspects (available barn area per ewe and barn ventilation) were similar across clusters as well. However, noticeable differences existed among the 4 clusters, which are described below.

\section{Cluster 1: Intensive, Specialized Farms $(n=18,27.3 \%)$}

The average flock consisted of 266 ewes, 120 lamb ewes, and 22 rams. Sheep-farming experience was the lowest $(5.1 \mathrm{yr})$; the difference in comparison with clusters 2 and 4 was statistically significant $(P \leq 0.05)$. The mean farm surface area was small (9.2) ha and differed significantly $(P \leq 0.05)$ from that of cluster 2 and 3 farms, which were 2.5 to 3.0 times larger. More than $60 \%$ of the land was rented and although mostly irrigated, on-farm feed production was low, due to small size. The labor force was around 1 worker per

Table 6. Frequencies (\%) and comparisons between the 4 clusters for categorical variables concerning farm characteristics and facilities

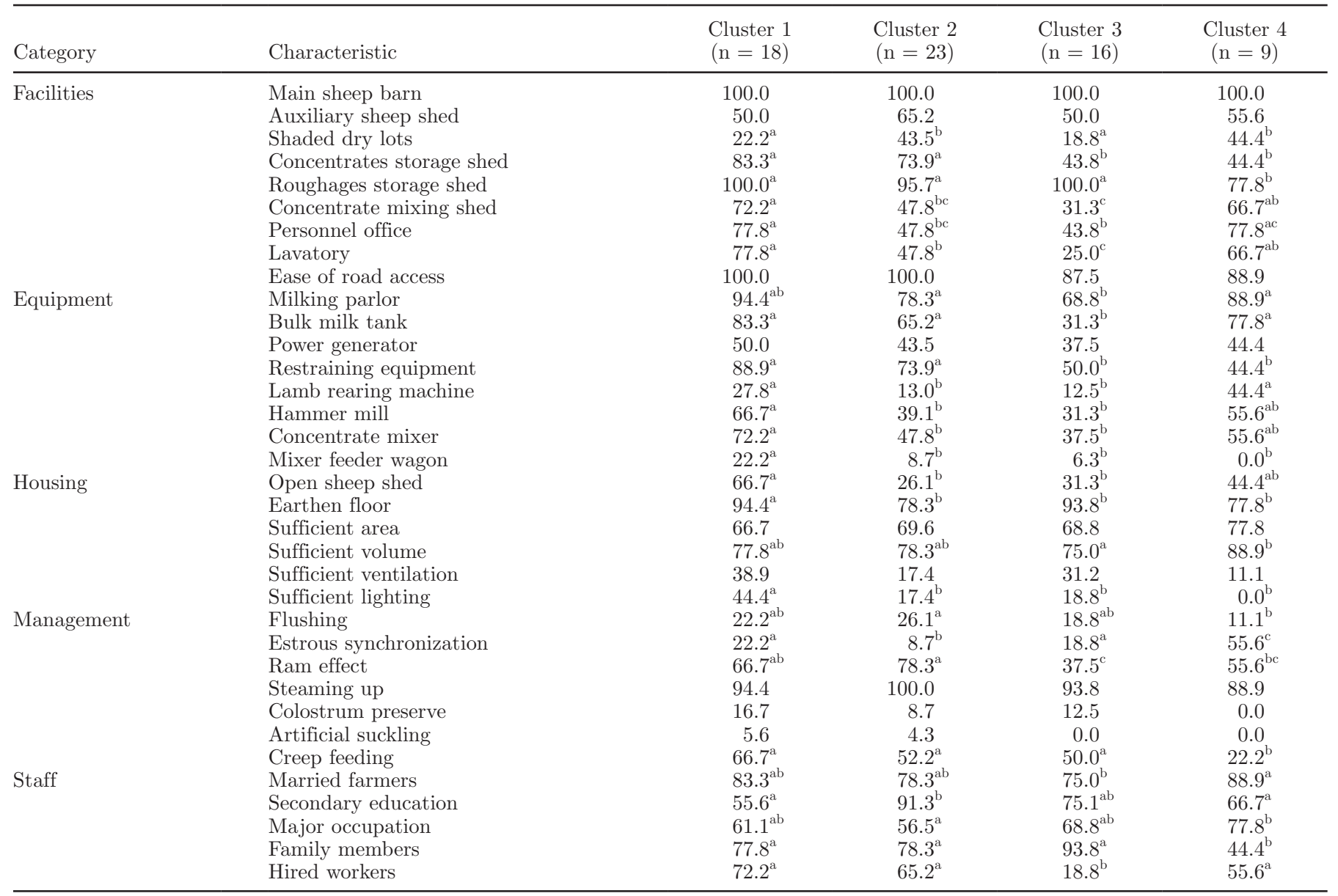

\footnotetext{
${ }^{a-c}$ Frequencies within a row with different superscripts differ $(P<0.05)$.
} 
Table 7. Means \pm standard deviations for continuous variables in the 4 clusters and comparisons between them

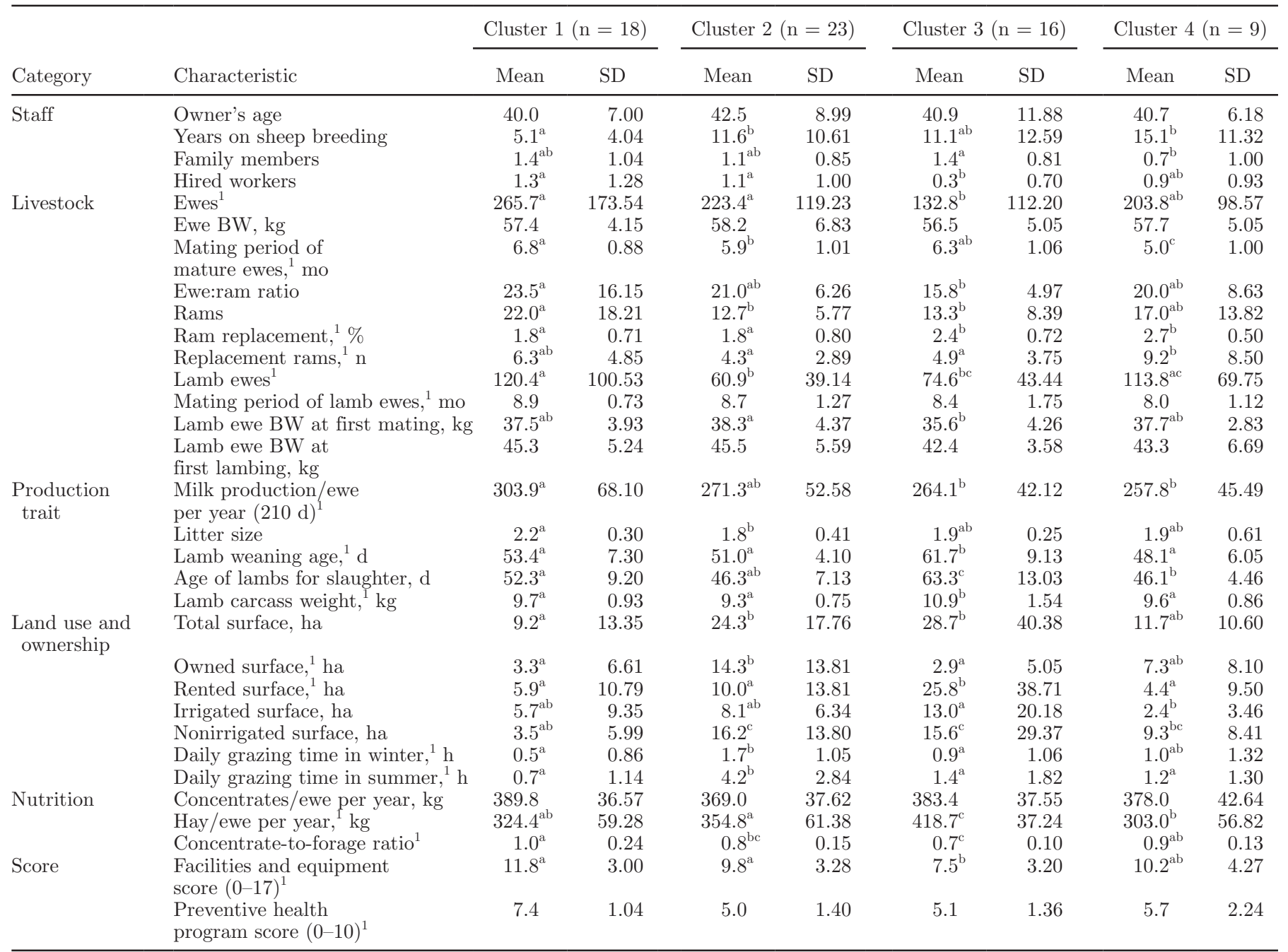

${ }^{\mathrm{a}-\mathrm{c}}$ Means within a row with different superscripts differ $(P<0.05)$.

${ }^{1}$ Variable used for the principal component analysis.

100 ewes. Milk production (303.9 kg/ewe per lactation) and litter size (2.2 lambs/lambing) was the highest among all clusters. Regarding milk production, the difference between cluster 1 and cluster 3 and 4 farms was statistically significant $(P \leq 0.05)$; the same was true regarding litter size compared with cluster 2 farms. On average, the mating month of mature ewes was July and differed significantly $(P \leq 0.01)$ from that of cluster 2 and 4 farms. Rams were used, on average, for $1.8 \mathrm{yr}$ and the difference in comparison with cluster 3 and 4 farms was significant $(P \leq 0.05$ and $P \leq 0.01$, respectively). The concentrate-to-forage ratio was the highest (1.0); the difference in comparison with cluster $2(0.8)$ and $3(0.7)$ farms was significant $(P \leq 0.05$ and $P \leq 0.001$, respectively). The use of ram effect was also common. The use of earthen floored, sufficiently lighted, open shed-type barns was the highest and dif- ferences in comparison with other cluster farms were statistically significant $(P \leq 0.05)$. Facilities/equipment and preventive health program scores (11.8 and 7.5, respectively) were the highest of all clusters and generally the differences were again statistically significant $(P<0.01)$.

\section{Cluster 2: Semi-Intensive, High-Investment Farms $(n=23,34.8 \%)$}

The average flock consisted of 223 ewes, 61 lamb ewes, and 13 rams. On average, sheep-farming experience exceeded $10 \mathrm{yr}$. The mean farm surface area was 24.3 ha, consisting of 14.3 ha of owned and 10.0 ha of rented land (a ratio of about 60:40); it differed significantly $(P \leq 0.05)$ from that of cluster 1 farms. Despite the fact that two-thirds of the land was not irrigated, 
on-farm feed production was satisfactory; about $30 \%$ of the farms were completely self-sufficient, considering either forage or cereal production. Moreover, these farms were the only to systematically graze their sheep. The labor force was around 1 worker per 100 ewes. On this cluster's farms, the percentage of lamb ewes $(27.3 \%)$ was similar to usual replacement rates of dairy ewes (20-30\%), suggesting no expansion intentions at the moment. Milk production was average $(271.3 \mathrm{~kg} /$ ewe per lactation) but litter size was low (1.8 lambs/ lambing). On average, the mating month of mature ewes was June and differed significantly from practices followed on the farms in clusters 1 and $4(P \leq 0.01$ and $P \leq 0.05$, respectively). Ram use was similar to that on cluster 1 farms and so were the differences with the other clusters. Replacement ewe BW at first mating was the highest of all farms and differed significantly $(P \leq 0.05)$ from that of cluster 3 farms. The concentrate-to-forage ratio was average $(0.8)$. The use of ram effect was more common than in other cluster farms. A closed barn with insufficient lighting was the norm in this cluster's farms, as was also the case with cluster 3 and 4 farms. Facilities/equipment and preventive health program scores (9.8 and 5.0, respectively) were average; the preventive health program score was significantly different $(P \leq 0.01)$ compared with that of cluster 1 farms.

\section{Cluster 3: Semi-Intensive, Low-Investment Farms ( $n=16,24.3 \%)$}

The average flock consisted of 133 ewes, 75 lamb ewes, and 13 rams. These farms were the smallest in flock size and the differences in comparison with cluster 1 and 2 farms were statistically significant $(P \leq 0.01$ and $P \leq 0.05$, respectively). On average, sheep-farming experience exceeded $10 \mathrm{yr}$. The labor force (around 1 worker per 78 ewes, due obviously to smaller flock size) was the highest of all clusters and consisted mainly of family members (Table 6), in contrast to all other farms where it was equally distributed between family members and hired workers. The mean farm surface area was 28.7 ha, consisting of 2.9 ha of owned and 25.8 ha of rented land (a ratio of about 10:90); it differed significantly $(P \leq 0.05)$ from that of cluster 1 farms. Despite the fact that more than half of the land was not irrigated, on-farm feed production was satisfactory, due to small flock size; about $37.5 \%$ of the farms were completely self-sufficient, considering either forage or cereal production. Milk production was low $(264.1 \mathrm{~kg} /$ ewe per lactation) and litter size (1.9 lambs/lambing) was average. On average, the mating month of mature ewes was June. Rams were used, on average, for $2.4 \mathrm{yr}$; the difference in comparison with cluster 1 and 2 farms was significant $(P \leq 0.05)$. Replacement ewe BW at first mating was the lowest of all farms and differed significantly $(P \leq 0.05)$ from that of cluster 2 farms. The use of ram effect was less common and the difference in comparison with cluster 1 and 2 farms was significant $(P \leq 0.05)$. A closed barn with insufficient lighting was the norm in this cluster's farms as was also the case with cluster 2 and 4 farms. Facilities and equipment scores were low (7.5) and preventive health program scores were just average (5.1); they were significantly different $(P \leq 0.001)$ from those of cluster 1 farms but not from those of the other clusters.

\section{Cluster 4: Semi-Intensive, Traditional Farms ( $n=9,13.6 \%)$}

The average flock consisted of 204 ewes, 114 lamb ewes, and 17 rams. On average, sheep-farming experience exceeded 15 yr. The labor force (around 1 worker per 127 ewes) was the lowest of all clusters. The mean farm surface area was 11.7 ha; more than $60 \%$ was owned and about $80 \%$ was not irrigated. Forage production was not a priority (only 1 farm was self-sufficient); on the other hand, 4 out of 9 farms produced all of the cereal grains needed as livestock feed. Milk production was low (257.8 kg/ewe per lactation) and litter size (1.9 lambs/lambing) was average. On average, the mating month of mature ewes was May and differed significantly from practices followed on farms of clusters 1,2 , and 3 ( $P \leq 0.001, P \leq 0.05$, and $P \leq 0.01$, respectively). Rams were used, on average, for $2.7 \mathrm{yr}$; the difference in comparison with cluster 1 and 2 farms was significant $(P \leq 0.01)$. The concentrate-to-forage ratio was average (0.9); the difference in comparison with cluster 3 farms (0.7) was significant $(P \leq 0.01)$. Creep feeding of lambs was rare and differed $(P \leq 0.05)$ from all other farms. The use of ram effect was less common and the difference in comparison with cluster 2 farms was significant $(P \leq 0.05)$. These farms were the only to use estrous synchronization schemes frequently. A closed barn with insufficient lighting was again the norm in this cluster's farms. Facilities/equipment and preventive health program scores (10.2 and 5.7, respectively) were average; the preventive health program score was significantly different $(P \leq 0.01)$ from that of cluster 1 farms.

\section{DISCUSSION}

Farm typology, applying a priori methods, is already used to characterize animal farming systems; differences can be easily identified when a network of farms is systematically followed for many years and data are continually available, as is the case in France (Anonymous, 2010). However, finding differences within the 
major systems is more delicate work and many years of data collection would be necessary before objectively chosen a priori criteria become evident.

Riedel et al. (2007) suggest that new production systems and management strategies, allowing increasing productivity while maximizing the use of natural resources, should be explored. This description fits nicely to the Chios sheep production systems. Delaying farm typification to collect and study relevant data is not an acceptable option; quantitative typology can provide a solution.

Published research using quantitative methods for typification of farming systems is limited. It includes a socioeconomic classification of German farm households (Gebauer, 1987) and CA of farming systems in North Central China (Hardiman, 1990), in Chile, and in Pakistan (Köbrich et al., 2003). More recently, CA was used by Usai et al. (2006) to characterize the goatfarming system in Sardinia and Milán et al. (2011) used multiple correspondence analysis to describe Awassi and Assaf dairy sheep farms in northwestern Spain. In the present study, principal component and k-means CA successfully identified 4 clusters that together accounted for $100.0 \%$ of the farms with distinct farming systems. Many interesting features arose from the analysis.

Although flock size does, in some cases, drive management decisions, it was not a farming system descriptive factor per se. Chios sheep flocks were smaller in size, compared with those of other European dairy sheep breeds like Lacaune and Awassi/Assaf (Morin et al., 2004; Milán et al., 2011) and larger than US dairy sheep flocks (Thomas, 2004). Despite this fact, the different approaches that exist within intensive systems were apparent in the present study as well. Although the flock sizes of cluster 1,2 , and 4 farms were similar, they were substantially different in many other aspects (e.g., farming experience, labor force, expansion strategies, milk production, surface area and type, on-farm feed production, facilities/equipment, and preventive health scores). The level of milk production was not a farming system descriptive factor per se, either. Cluster 1 and 2 farms, which clearly differ in most other aspects, had similar milk production per ewe per year. Cluster 3 and 4 farms, which also had similar milk production per ewe per year, differed in labor availability and type, surface ownership and type, on-farm feed production, and investment in facilities and equipment. Milk production must be considered a result of management decisions but not an indication of a different farming system. When using a priori classification methods, though, flock size and milk production, probably being the first 2 issues to discuss with every dairy farmer around the world, are commonly used as typical descriptive factors; according to our results, this should not be the case.

Land availability, ownership, type, and use are major factors differentiating farming systems. Chios breed dairy sheep farms are considerably smaller in size than their European or US counterparts (Morin et al., 2004; Thomas, 2004; Milán et al., 2011). Yet, the same basic principles were evident, namely, the need for on-farm feed production and the extent of pasture use. In our set of farms, 4 different farmer attitudes were evident in this respect (Gelasakis et al., 2010): 1) farming disrupts sheep breeding; feed (forage and concentrate) should be purchased and economies of scale will decrease costs, 2 ) only exercise/pasture land is necessary; at least part of the feed must be home-grown to decrease costs, 3) pasture is essential to sheep; on-farm feed production decreases costs, and 4) large-scale farming (feed production and cash crops) does not disrupt sheep breeding; all feed must be produced on-farm to decrease costs. Farms of cluster 1 mainly expressed attitude 1; 10 of the farms $(15.2 \%)$ were no-land farms. Although this attitude may be an expression of low sheep-farming experience, as is the case in this cluster, it is undoubtedly a management decision that characterizes a farming system. The rest of cluster 1 farms were small-sized farms, owned by farmers expressing attitude 2. Farmers in cluster 2 expressed mainly attitude 3 . Temporary swards were arranged on owned land around the farmstead, making flock moving and grazing easy, as the Chios breed is not adapted to extensive grazing. In animal agriculture, pasture use is an element that certainly differentiates farming systems. Moreover, grazing has strong implications with animal welfare and biosecurity issues. Farmers of cluster 3 expressed mainly attitude 4: grazing is rather for exercise, not feeding, and they preferred not to own the land used for feed production, minimizing capital investments and retaining flexibility (feed production and cash crops). Cluster 4 farmers expressed mainly attitude 2. They seemed to consider sheep farming and crop production as 2 different enterprises within the same farm, as they were not focused on feed production.

The ratio ewes per hectare of available land, if properly characterized, could be another farming system descriptor, as well. However, comparisons within specific and between different data sets require factors like farmer technical skills, input levels, and agricultural potential of the land to be carefully accounted for. Clearly, this cannot be done using questionnaires; it requires in-depth investigation and analysis by expert personnel, which is obviously prohibitive in large-scale research studies. On the other hand, feeding systems, and especially, forage-to-concentrate ratios, integrating 
pasture use and on-farm forage production, do provide solid information regarding the farming system. In the present study, farm clusters were significantly different in this respect. Results also imply that differences in the efficiency of turning feed into milk are present; when the amount of concentrates and hay per ewe per year (Table 7), combined with the extent of pasture use, are taken into account, farms of cluster 1 seem more efficient than those of clusters 2 and 3.

Flock expansion strategy was another descriptor of the farming system. Cluster 1 farms were expanding, trying to reclaim their investments in facilities and equipment and cluster 3 and 4 farms were expanding probably to compensate for their lower milk production. Higher flock turnover rates could be linked to faster genetic improvement, as well. Higher ram replacement rates on cluster 1 and 2 farms, which have higher milk production per ewe, may also be indicative of such a policy. At present, this is only a speculation, as ram breeding values are not yet available.

Investment in facilities and equipment differentiated cluster 1 from cluster 3 , the latter representing an effort to reduce capital inputs, and perhaps, operational costs. The difference in milk produced per ewe per year, in favor of cluster 1 , cannot be attributed to these 2 different investment approaches when significant feeding program differences exist. On the other hand, it makes profitability comparisons an interesting issue. Differences in preventive flock health programs were significant between farms of cluster 1 and those of all other clusters. Although existent, it is difficult to attribute differences in milk production on more complete health programs without taking into account feeding program differences and actual disease pressure; farms of cluster 1 may have been overreacting on this issue, frequent anthelmintic treatments and vaccination against contagious agalactia probably not being necessary in zerograzed flocks.

The present analysis resulted in 2 major farming systems based on land use and feed/crop production, each with 2 subgroups based on other management practices. Cluster 1 farms are newly established, intensive, wellequipped, specialized dairy sheep farms capitalizing on high milk production based on modern management procedures. Their focus is clearly on livestock and they are still evolving toward a larger flock size. Cluster 2 farms are well established and undoubtedly more complete economic units, with balanced sheep and feed/ crop production. Their progress lies in improving feed efficiency and health management, giving them a more professional profile. Cluster 3 farms are focusing more on arable crops (although with rented land) than on sheep farming; this seemed to change as they were actually expanding their flock size. We anticipate they will evolve toward cluster 2 farms, as it seems unlikely to abandon arable farming; expanding flock size first justifies their eventual investments in facilities and equipment. Cluster 4 farms represent a rather conservative form of Chios sheep breeding. In many aspects, they are close to cluster 1 farms, as they choose not to focus on feed/crop production. Improvement of management skills and reasonable investments would get them even closer.

The final step would be to conduct a profitability analysis among different clusters, exploring and discovering the most beneficial levels of intensified management and capital investment. This is a crucial step, making strengths and weaknesses of each system evident and providing farmers, bankers, and agriculture policy makers the benefit of informed decisions and promoting agricultural development at the national and, potentially, international levels.

Future research should include other, less-intensive, pasture-based sheep and goat farming systems in Greece, using the same methodology. Considering the number of local breeds and the extreme range of land and climatic conditions, this is, undoubtedly, a difficult task. However, it is considered essential to preserve the genetic diversity and the wealth of traditional products through profitable farming. The collection of necessary data is time consuming and personnel with high-level expertise are required, but the accuracy of the procedure is definitely cost-effective.

\section{CONCLUSIONS}

The structural characteristics for the description of farming systems of Chios sheep farms in Greece are mainly associated with the availability and use of land and secondary with capital investment and management skills. The combination of principal component and k-means CA is a very powerful assessment tool for the a posteriori typification of farming systems and should be advantageously used in similar studies.

\section{ACKNOWLEDGMENTS}

The authors thank the Chios Sheep Breeders' Cooperative Macedonia for the collaboration. The first author acknowledges financial support from the Greek State Scholarships Foundation (Athens, Greece). Financial support was also provided by CEVA Hellas PLC (Athens, Greece).

\section{REFERENCES}

Anonymous. 2010. Typologie des systèmes d'élevages bovin à Pays de la Loire. Accessed March 2011. http://www.agrilianet.com/ 
publications/detail-publication/actualite//bovins-typolo-gie-dessystemes-delevages-bovins-en-pays-de-la-loire.html.

Coop, I. E. 1982. Intensive grassland systems. Page 351 in World Animal Science-Subseries C: Production system approach. Elsevier, Amsterdam, the Netherlands.

Gebauer, R. H. 1987. Socio-economic classification of farm households - Conceptual methodical and empirical considerations. Eur. Rev. Agric. Econ. 14:261-283.

Gelasakis, A. I., G. E. Valergakis, P. Fortomaris, and G. Arsenos. 2010. Farm conditions and production methods in Chios sheep flocks. J. Hell. Vet. Med. Soc. 61:111-119.

Haenlein, G. F. W. 2001. Past, present and future perspectives of small ruminant dairy research. J. Dairy Sci. 84:2097-2115.

Hardiman, R. T., R. Lacey, and Y. M. Yi. 1990. Use of cluster analysis for the identification and classification of farming systems in Qingyang County, Central North China. Agric. Syst. 33:115-125.

Hatziminaoglou, I., N. Polyzos, I. Magoulas, and I. Boyazoglou. 1992. Législation, utilisation et perspectives: Cas de la Grèce. Pages 91-116 in Terres collectives en Méditerranée: Histoire, législation, usages et modes d'utilisation par les animaux. A. Bourbouze and R. Rubino, ed. Ars Grafica, Rome, Italy.

Iraizoz, B., M. Gorton, and S. Davidova. 2007. Segmenting farms for analysing agricultural trajectories: A case study of the Navarra region in Spain. Agric. Syst. 93:143-169.

Kaiser, H. F. 1960. The application of electronic computers to factor analysis. Educ. Psychol. Meas. 20:141-151

Köbrich, C., T. Rehman, and M. Khan. 2003. Typification of farming systems for constructing representative farm models: Two illustrations of the application of multi-variate analyses in Chile and Pakistan. Agric. Syst. 76:141-157.
Kostrowicki, J. 1977. Agricultural typology concept and method. Agric. Syst. 2:33-45.

Milán, M. J., G. Caja, R. González-González, A. M. Fernández-Pérez, and X. Such. 2011. Structure and performance of Awassi and Assaf dairy sheep farms in northwestern Spain. J. Dairy Sci. 94:771784 .

Morand-Fehr, P., and J. Boyazoglu. 1999. Present state and future outlook of the small ruminant sector. Small Rumin. Res. 34:175-188.

Morin, E., C. Cassignol, and J. Fraysse. 2004. La production de Lait de Brebis en France. Diversité des Systèmes d'Exploitation. Institut de l'Elevage, Paris, France.

Papachristoforou, C., and M. Markou. 2006. Overview of the economic and social importance of the livestock sector in Cyprus with particular reference to sheep and goats. Small Rumin. Res. 62:193-199.

Riedel, J. L., I. Casasús, and A. Bernués. 2007. Sheep farming intensification and utilization of natural resources in a Mediterranean pastoral agro-ecosystem. Livest. Sci. 111:153-163.

Thomas, D. L. 2004. Overview of the dairy sheep sector in Canada and the United States. Pages 166-180 in Proc. 10th Annual Great Lakes Dairy Sheep Symposium, Hudson, WI.

Usai, M. G., S. Casu, G. Molle, M. Decandia, S. Ligios, and A. Carta. 2006. Using cluster analysis to characterize the goat farming system in Sardinia. Livest. Sci. 104:63-76.

Ward, J. Jr. 1963. Hierarchical grouping to optimize an objective function. JASA 58:236-244.

Zygoyiannis, D. 2006. Sheep production in the world and in Greece. Small Rumin. Res. 62:143-147. 